\title{
Association between thrombophilia and ischemic stroke: when is work-up for hypercoagulable state indicated?
}

\author{
Kah Poh Loh ${ }^{1}$, Sheryl Ramdass ${ }^{2}$, Leslie Howard ${ }^{3}$ and Saurabh Dahiya ${ }^{3}$ \\ ${ }^{1}$ Division of Hematology/Oncology, James P. Wilmot Cancer Institute, University of Rochester/Strong Memorial Hospital, USA \\ ${ }^{2}$ Division of General Internal Medicine, Department of Medicine, Baystate Medical Center/Tufts University, USA \\ ${ }^{3}$ Division of Hematology and Oncology, Baystate Medical Center/Tufts University, USA
}

\section{Introduction}

Hypercoagulable state or thrombophilia are disorders of the hemostatic mechanisms that increases the risk of thrombosis, both arterial and venous [1]. Inherited thrombophilia is a well-recognized risk factor for venous thrombosis, but its association with arterial thrombosis has not been clearly established. There are also various acquired conditions that are associated with hypercoagulable state. Case-control studies and meta-analyses investigating thrombophilia and ischemic stroke have not been consistent [2]. Despite lack of strong evidence in literature many clinicians order these tests as part of ischemic stroke work-up [3]. We report a case of cryptogenic stroke and review the challenges associated with the hypercoagulable state in such common clinical scenarios. We also review the evidence-based recommendations about the use of coagulation tests in the work-up for ischemic stroke.

\section{Case report}

A 56 year-old right-handed male presented with acute onset of loss of vision in his left eye associated with a posterior headache. He denied any weakness, abnormal or loss of sensation, speech disturbance or scalp tenderness. He had no previous history of migraine headaches. He past medical history was only significant for hyperlipidemia treated with fenofibrate and newly diagnosed obstructive sleep apnea. He had successfully quit smoking tobacco about 30 years ago. There was no known personal or family history of stroke or thromboembolic disease. He did endorse family history of thyroid cancer in two of his siblings. Physical examination was only remarkable for uncontrolled blood pressure at 184/104 and left superior quadrantanopia on neurological assessment. Other cranial nerve, peripheral motor and sensation testing as well as gait assessment were intact. Admission laboratories including complete blood count $(\mathrm{CBC})$, comprehensive metabolic panel (CMP) and erythrocyte sedimentation rate (ESR) were within normal limits. Hyper-acute computer tomography (CT) of brain demonstrated no acute intracranial hemorrhage and subsequent MRI head demonstrated a $3.6 \mathrm{~cm}$ area of acute ischemia involving the right occipital and temporal occipital junction (Figure 1). Electrocardiogram showed sinus rhythm and transthoracic echocardiogram with bubble study demonstrated preserved ejection fraction without evidence of patent foramen ovale or valvular abnormalities. His hemoglobin A1C was $4.5 \%$ and low-density lipoprotein was $117 \mathrm{mg} / \mathrm{dL}$. Neurology was consulted with recommendations for the following investigations. CT angiogram of head and neck demonstrated mild bilateral carotid origin plaque. A subsequent 30-day loop recorder showed no evidence of arrhythmia and an implantable loop recorder was subsequently placed. Given his extensive work up without any explanation for his stroke etiology, a hypercoagulable evaluation was undertaken. All coagulation testing returned within normal limits except for slightly above the upper limit of normal homocysteine levels (Table 1). He was discharged on aspirin, clopidrogel along with lisinopril for blood pressure control with recommendation to abstain from driving and outpatient Neurology follow up.

\section{Discussion}

Ischemic stroke is commonly due to cardioembolism, large vessel atherothromboembolism and small vessel occlusive disease. Cryptogenic stroke constitutes approximately $40 \%$ of ischemic stroke and is defined as brain infarction that is not attributable to the sources above despite extensive vascular, cardiac, and serologic evaluation [4]. These may be due to insufficient tests ordered, tests not performed in due time or that causes are truly uncertain $[5,6]$. Evidence has shown that some patients with cryptogenic stroke may have underlying hypercoagulable state $[7,8]$. Hypercoagulable state can be divided into inherited versus acquired conditions. Common conditions associated with hypercoagulable states are shown in Table 2.

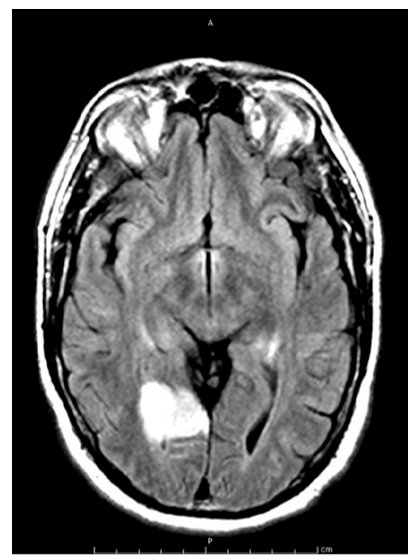

Figure 1. MRI brain with and without contrast showing a $3.6 \mathrm{~cm}$ area of acute ischemia involving the right occipital and temporal occipital junction.

Correspondence to: Saurabh Dahiya, Division of Hematology and Oncology, Baystate Medical Center/Tufts University, 376 Birnie Avenue, Springfield, MA, USA; E-mail: drsaurabhdahiya@gmail.com

Received: February 07, 2016; Accepted: March 15, 2016; Published: March 18, 2016 
Table 1. Summary of patient's hypercoagulable evaluation with normal reference ranges.

\begin{tabular}{|c|c|c|}
\hline Coagulation parameter & Results & Reference range, units \\
\hline INR & 1.1 & $0.9-1.1$ \\
\hline PT & 11 & $9.7-12.2, \mathrm{sec}$ \\
\hline Homocysteine & 16.1 & $5-15, \mu \mathrm{mol} / \mathrm{L}$ \\
\hline Factor VIII & 114 & $50-200, \%$ \\
\hline Protein C & 114 & $74-151, \%$ \\
\hline Protein S & 100 & $56-124, \%$ \\
\hline Antithrombin III & 98 & $75-135, \%$ \\
\hline Factor V Leiden mutation & Negative & N/a \\
\hline Factor II mutation & Negative & N/a \\
\hline
\end{tabular}

Table 2. Inherited and non-inherited conditions associated with hypercoagulable States.

\section{Inherited conditions}

Protein C (PC) deficiency

Proteins S (PS) deficiency

Antithrombin (AT) deficiency

Factor V Leiden (FVL) mutation

Prothrombin G20210A gene mutation

Increased homocysteine level

Increased fibrinogen level or dysfibrinogenemia

Increased lipoprotein (a)

\section{Non inherited conditions}

Antiphospholipid syndrome (lupus anticoagulant, anticardiolipin antibodies, anti- $\beta(2)$ glycoprotein)

Cancer (Trousseau syndrome)

Increased lipoprotein (a)

Myeloproliferative disorders (essential thrombocytosis, polycythemia vera)

In a study, the probabilities of coagulation defects in ischemic stroke patients were found to be low: $3 \%$ in lupus anticoagulant $(8 \%$ in patients aged $<50$ years), $17 \%$ in anticardiolipin antibodies $(21 \%$ in patients aged $<50$ years), $7 \%$ in activated protein $\mathrm{C}$ resistant/Factor $\mathrm{V}$ Leiden ( $11 \%$ in patients aged $<50$ years) and $4.5 \%$ in prothrombin mutation $(5.7 \%$ in patients aged $<50$ years) [9]. The prevalence of inherited thrombophilia in ischemic stroke patients was reported to be similar to general population, with ethnic differences in the markers $[9,10]$. On the other hand, few studies suggested association between increased homocysteine level and ischemic stroke caused by largeartery atherosclerosis and small-artery disease $[11,12]$.

In a single center study, it was found that $31 \%$ of patients with ischemic stroke were tested for coagulopathies, and $29 \%$ of them were unlikely to alter therapeutic decisions [3]. Widespread testing can lead to incidental findings of abnormalities, some of which are difficult to interpret in the setting of acute ischemic events or anticoagulation. There is also added cost of diagnostic testing, leading to unnecessary anticoagulation and also generate anxiety in both patients and families [1]. Of note, the functional assays for Protein C, Protein S and AT deficiency are affected by acute thrombosis, acute phase reactant and in the setting of anticoagulation therefore the assays should be repeated at least 3 months after the acute thrombotic event [13].

We propose ordering these tests in the following settings:

Family or personal history of clotting events (specially venous) at a young age or in unusual locations with no clear explanation for stroke
Inherited thrombophilia is associated with unprovoked venous thromboembolism (VTE) but the evidence is conflicting for arterial thrombosis, as shown in an extensive review article by Morris et al. [2]. The cutoff age to define young and old is not clearly delineated, but ischemic stroke occurring in patients younger than 44 years of age is considered young [1]. Ischemic stroke secondary to an underlying hypercoagulable disorder is more common in younger patients (10$15 \%)$, but cardioembolism remains the most common etiology [1]. One study found that younger age is a predictor for ordering specialized coagulation tests [3]. Due to the inconsistent results, testing for inherited thrombophilia in the setting of acute ischemic stroke is not recommended unless there is presence of history of unprovoked VTE, history of an unprovoked VTE, VTE in an unusual location, family history of a VTE, thrombosis at a young age (younger than 45), and frequent thrombotic recurrences [14].

\section{Signs and symptoms suggestive of antiphospholipid syndrome (Table 3) [15]}

Antiphospholipid syndrome was found to be a major risk factor for arterial thrombotic events in young women, with a higher risk in patients tested positive for lupus anticoagulant compared to anticardiolipin antibodies, although the latter is less common [1]. Rahemtullah et al. reviewed 14 prospective stroke or TIA studies, 8 of which identified a significant finding in association with an antiphospholipid antibody [16]. Of note these antibodies can fluctuate over time, therefore the titers should be recheck later to confirm the diagnosis [13].

\section{Cryptogenic stroke with signs or symptoms suggestive of an occult malignancy or myeloproliferative state}

In the study by Cocho et al., $2.1 \%$ of patients with acute ischemic stroke were found to have occult malignancy (OM), and 5.3\% for patients with cryptogenic stroke. Patients with and without OM had fibrinogen level of $572 \mathrm{mg} / \mathrm{dL}$ versus $457 \mathrm{mg} / \mathrm{dL}(P=.045)$ and CRP level of $17.7 \mathrm{mg} / \mathrm{L}$ versus $4.8 \mathrm{mg} / \mathrm{L}(P=.001)$, respectively. Another study by Kim et al. found a $20.4 \%$ of patients with cryptogenic stroke had active cancer at the time of stroke. The common sites were lung, lymphoma, hepatobiliary and gastrointestinal $[17,18]$. Clues to $\mathrm{OM}$ in these patients include high D-dimer levels (odd ratio 1.11 per $1 \mu \mathrm{g} / \mathrm{mL}$ increase) and multiple ischemic lesions in multiple vascular territories as shown by two retrospective studies [17]. Therefore, patients with acute ischemic stroke should be encouraged to undergo age appropriate screening for cancer. If there are any signs or symptoms suggestive of an occult malignancy $(\mathrm{OM})$ with no identifiable cause for ischemic stroke

Table 3. Common manifestations of antiphospholipid syndrome.

\begin{tabular}{|l|c|}
\hline Manifestations & Percentage (\%) \\
\hline Deep vein thrombosis & 38.9 \\
\hline Arthralgia & 38.7 \\
\hline Arthritis & 27.1 \\
\hline Early fetal losses $(<10$ weeks) & 35.4 \\
\hline Thrombocytopenia $(<100,000 / \mu 1)$ & 29.6 \\
\hline Livedo reticularis & 24.1 \\
\hline Stroke & 19.8 \\
\hline Migraine & 20.2 \\
\hline Pulmonary embolism & 14.1 \\
\hline Superficial thrombophlebitis in legs & 11.7 \\
\hline Transient ischemic attack & 11.1 \\
\hline Valve thickening/dysfunction & 11.6 \\
\hline Late fetal losses $(\geq 10$ weeks $)$ & 16.9 \\
\hline
\end{tabular}


and elevated D-dimer, there should be low threshold for appropriate work-up $[17,19]$. In patients who have a family history of specific cancer type, screening for the respective cancer can be considered.

Additionally, any obvious abnormalities in CBC, such as persistent high platelet count, very high hematocrit and hemoglobin, should be further evaluated for myeloproliferative neoplasms such as essential thrombocytosis (ET) and polycythemia vera (PV). Ischemic stroke constitutes $30 \%-40 \%$ of all thrombotic events in PV patients [20].

\section{Conclusion}

In our patient, work-up for thrombophilia was performed secondary to his relatively young age with the presence of hyperlipidemia that is treated with fenofibrate with no clear explanation for the cause of his stroke. His homocysteine level was slightly elevated, but there is no clear evidence that lowering homocysteine level reduces the risk of subsequent stroke [21]. He did not exhibit any symptoms and signs of lupus therefore antiphospholipid titers were not performed. Symptoms and signs for occult malignancy were negative, however we recommended that he should at least undergo age appropriate cancer screening with colonoscopy.

\section{References}

1. Ng KW, Loh PK, Sharma VK (2011) Role of investigating thrombophilic disorders in young stroke. Stroke Res Trea t2011: 670138. [Crossref]

2. Morris JG, Singh S, Fisher M (2010) Testing for inherited thrombophilias in arterial stroke: can it cause more harm than good? Stroke 41: 2985-2990. [Crossref]

3. Bushnell C, Siddiqi Z, Morgenlander JC, Goldstein LB (2001) Use of specialized coagulation testing in the evaluation of patients with acute ischemic stroke. Neurology 56: 624-627. [Crossref]

4. Adams HP Jr, Bendixen BH, Kappelle LJ, Biller J, Love BB, et al. (1993) Classification of subtype of acute ischemic stroke. Definitions for use in a multicenter clinical trial. TOAST. Trial of Org 10172 in Acute Stroke Treatment. Stroke 24: 35-41. [Crossref]

5. Lee BI, Nam HS, Heo JH, Kim DI; Yonsei Stroke Team (2001) Yonsei Stroke Registry. Analysis of 1,000 patients with acute cerebral infarctions. Cerebrovasc Dis 12: $145-151$. [Crossref]

6. Sacco RL, Ellenberg JH, Mohr JP, Tatemichi TK, Hier DB, et al. (1989) Infarcts of undetermined cause: the NINCDS Stroke Data Bank. Ann Neurol 25: 382-390. [Crossref]

7. Kenet G, Sadetzki S, Murad H, Martinowitz U, Rosenberg N, et al. (2000) Factor V
Leiden and antiphospholipid antibodies are significant risk factors for ischemic stroke in children. Stroke 31: 1283-1288. [Crossref]

8. Voetsch B, Damasceno BP, Camargo EC, Massaro A, Bacheschi LA, et al. (2000) Inherited thrombophilia as a risk factor for the development of ischemic stroke in young adults. Thromb Haemost 83: 229-233. [Crossref]

9. Hankey GJ, Eikelboom JW, van Bockxmeer FM, Lofthouse E, Staples N, et al. (2001) Inherited thrombophilia in ischemic stroke and its pathogenic subtypes. Stroke 32: 1793-1799. [Crossref]

10. Jerrard-Dunne P, Evans A, McGovern R, Hajat C, Kalra L, et al. (2003) Ethnic Differences in Markers of Thrombophilia Implications for the Investigation of Ischemic Stroke in Multiethnic Populations: The South London Ethnicity and Stroke Study. Stroke 34:1821-6. [Crossref]

11. Tan NC, Venketasubramanian N, Saw SM, Tjia HT (2002) Hyperhomocyst(e)inemia and risk of ischemic stroke among young Asian adults. Stroke 33: 1956-1962. [Crossref]

12. Eikelboom JW, Hankey GJ, Anand SS, Lofthouse E, Staples N, et al. (2000) Association between high homocyst(e)ine and ischemic stroke due to large- and smallartery disease but not other etiologic subtypes of ischemic stroke. Stroke 31:1069-75. [Crossref]

13. Bushnell CD, Goldstein LB (2000) Diagnostic testing for coagulopathies in patients with ischemic stroke. Stroke 31: 3067-3078. [Crossref]

14. [No authors listed] (1997) Inherited thrombophilia: memorandum from a joint WHO/ International Society on Thrombosis and Haemostasis meeting. Bull World Health Organ 75: 177-189. [Crossref]

15. Gómez-Puerta JA, Cervera R (2014) Diagnosis and classification of the antiphospholipid syndrome. J Autoimmun 48-49: 20-5. [Crossref]

16. Rahemtullah A, Cott EMV (2009) Hypercoagulation Testing in Ischemic Stroke [Internet]. Archives of Pathology \& Laboratory Medicine Online. [cited 2015 Sep 3].

17. Kim SJ, Park JH, Lee MJ, Park YG, Ahn MJ, et al. (2012) Clues to occult cancer in patients with ischemic stroke. PLoS One 7: e44959. [Crossref]

18. Cocho D, Gendre J, Boltes A, Espinosa J, Ricciardi AC, et al. (2015) Predictors of occult cancer in acute ischemic stroke patients. J Stroke Cerebrovasc Dis 24: 13241328. [Crossref]

19. Kwon HM, Kang BS, Yoon BW (2007) Stroke as the first manifestation of concealed cancer. J NeurolSci 258: 80-83. [Crossref]

20. Falanga A, Marchetti M (2012) Thrombotic disease in the myeloproliferative neoplasms. Hematology Am Soc Hematol Educ Program 2012: 571-581. [Crossref]

21. Toole JF, Malinow MR, Chambless LE, Spence JD, Pettigrew LC, et al. (2004) Lowering homocysteine in patients with ischemic stroke to prevent recurrent stroke, myocardial infarction, and death: the Vitamin Intervention for Stroke Prevention (VISP) randomized controlled trial. JAMA 291: 565-75. [Crossref]

Copyright: (C2016 Loh KP. This is an open-access article distributed under the terms of the Creative Commons Attribution License, which permits unrestricted use, distribution, and reproduction in any medium, provided the original author and source are credited. 